\title{
Pituitary adenylate cyclase-activating peptide 38 a potent endogenously produced dilator of human airways
}

\author{
J. Kinhult*, J.A. Andersson*, R. Uddman*, P. Stjärne**, L-O. Cardell*,
}

Pituitary adenylate cyclase-activating peptide 38 a potent endogenously produced dilator of human airways. J. Kinhult, J.A. Andersson, R. Uddman, P. Stjärne, L-O. Cardell. C)ERS Journals Ltd 2000

ABSTRACT: Pituitary adenylate cyclase-activating peptide (PACAP) 38 displays several biological activities relevant to obstructive airway disease.

In this study, the occurrence of PACAP 38 in human small bronchi and corresponding pulmonary arteries was analysed immunocytochemically. The dilatory effects of this peptide on the same structures were also studied in vitro.

A moderate number of PACAP-like immunoreactive nerve fibres was seen in association with bronchial and vascular smooth muscle and around seromucous glands. PACAP 38 caused a concentration-dependent relaxation of precontracted bronchial and pulmonary arterial segments. The maximal relaxation was more pronounced in the airways than in the arteries, whereas the potency in both was identical. PACAP 38 caused relaxation of all segments tested (nine patients), whereas vasoactive intestinal polypeptide (VIP) failed to cause relaxation of bronchial segments from six of nine patients. Both PACAP and VIP dilated all pulmonary arterial segments tested.

In conclusion, pituitary adenylate cyclase-activating peptide 38 is a potent dilator of human bronchi and is present in the human lung. Pituitary adenylate cyclaseactivating peptide 38 may, therefore, play a role in the endogenous regulation of airway tone. The inhibitory effects of pituitary adenylate cyclase-activating peptide 38 are more consistent than those of the related neuropeptide vasoactive intestinal polypeptide, perhaps reflecting a difference in susceptibility to degrading enzymes. Eur Respir J 2000; 15: 243-247.
*Dept of Otorhinolaryngology, Malmö General Hospital, Malmö, Sweden. **Dept of Otorhinolaryngology, Karolinska Institute, Stockholm, Sweden.

Correspondence: L-O. Cardell, Dept of Otorhinolaryngology, Malmö University Hospital, S-205 02 Malmö, Sweden. Fax: 4640336229

Keywords: Bronchi, in vitro pharmacology, lung, pituitary adenylate cyclase-activating peptide, pulmonary artery, vasoactive intestinal polypeptide

Received: March 61999

Accepted after revision October 191999

This work was supported by grants from the Swedish Medical Research Council (projects Nos K95-17P-11432-01A and K95-17F-11294-01), the Swedish Society of Medicine, the Swedish Society of Medicine Research, the Swedish Heart Lung Foundation, the Swedish Association for Allergology, the Harald Jeansson Foundation, the Tore Nilsson Foundation for Medical Research, the Österlund Foundation and the University of Lund.
Pituitary adenylate cyclase-activating peptide (PACAP) is a neuropeptide of the vasoactive intestinal polypeptide (VIP)/secretin/glucagon family $[1,2]$. PACAP occurs in two endogenous forms, PACAP 27 and PACAP 38, PACAP 27 constituting the N-terminal, "VIP-like", portion of PACAP 38 [2]. The name derives from the observation that they are powerful stimulants of adenylate cyclase in anterior pituitary cells in culture, being $>1,000$ times more potent than VIP [3]. PACAP 27 and PACAP 38 display several biological activities that may be relevant to the understanding and treatment of obstructive airway diseases such as asthma and chronic obstructive pulmonary disease. These activities include inhibition of airway and vascular smooth muscle tone in different animal models as well as modulation of inflammatory cell activity [4]. PACAP-containing nerve fibres are found in association with bronchial smooth muscle in primates and rodents $[5,6]$ and appear to be more abundant than VIP fibres in human bronchi [7], supporting a role for PACAP in the endogenous control of bronchial smooth muscle tone. The findings of high-affinity binding sites for both receptors in the rat lung further support this idea $[8,9]$.

In the present study, it was investigated whether PACAP-like immunoreactivity was also present in the human lung and the effect of PACAP 38 on isolated airway and pulmonary arterial segments from patients undergoing pulmonary surgery was evaluated.

\section{Materials and methods}

Human lung tissue was obtained during lung lobectomy from donors (age range 50-72 yrs) with lung cancer. All donors had a history of smoking and reported symptoms of chronic bronchitis at the time of surgery. A macroscopically normal portion of the lung, located $\geq 5 \mathrm{~cm}$ from the palpable edge of the tumour, was excised and immersed in either an ice-cold fixative solution for use in immunocytochemical investigations or a cold $\left(4^{\circ} \mathrm{C}\right)$ buffer solution for use in in vitro pharmacological evaluations. Approval for this study was granted by the local Ethics Committee at Malmö University Hospital, Sweden.

\section{Immunocytochemical investigations}

The specimens were immersed in a fixative solution composed of $2 \%$ formaldehyde and $0.2 \%$ picric acid and buffered to $\mathrm{pH} 7.2$ with $0.1 \mathrm{M}$ phosphate buffer. After $12 \mathrm{~h}$, the specimens were rinsed in Tyrode's solution containing $10 \%$ sucrose for $48 \mathrm{~h}$ frozen on dry ice and sectioned in a cryostat at $10-\mu \mathrm{m}$ thickness. The sections were processed for the immunocytochemical demonstration of PACAP 38 using indirect immunofluorescence. The PACAP antiserum (B57-1; Eurodiagnostica, Malmö, Sweden) was raised in a rabbit against ovine PACAP 38 and used at a dilution of 1:640. The sections were exposed to the peptide 
antiserum in a moist chamber for $24 \mathrm{~h}$ at $4{ }^{\circ} \mathrm{C}$. The site of the antigen/antibody reaction was revealed by application of fluorescein isothiocyanate-labelled antibodies against immunoglobulin G (Dakopatts, Copenhagen, Denmark) at a dilution of $1: 320$ for $1 \mathrm{~h}$ at room temperature $\left(22^{\circ} \mathrm{C}\right)$. Control sections were exposed to primary antiserum that had been preabsorbed with excess amounts of antigen (10 $\mu \mathrm{g}$ synthetic peptide. $\mathrm{mL}$ diluted antiserum ${ }^{-1}$ ). In addition, absorption tests showed that the PACAP 38 antiserum does not cross-react with VIP, peptide histidine isoleucine, helodermin, helospectin, bombesin or substance P. However, cross-reaction with other peptides or proteins sharing amino acid sequences with the examined peptide cannot be excluded. Therefore, it is appropriate to refer to the immunoreactive material as PACAP-like.

\section{In vitro experiments}

Small human bronchi and corresponding pulmonary arteries were dissected out (5th-7th branches, with an internal diameter of $\sim 2-4 \mathrm{~mm}$ ). Care was taken to avoid excess manipulation of the tissue in order to minimize damage to the walls. Each segment was divided into two or three matching cylindrical segments. The specimens were used in experiments within 1-3 h of dissection. The segments were immersed in small $(2.5 \mathrm{~mL})$ water-mantled temperaturecontrolled $\left(37^{\circ} \mathrm{C}\right)$ tissue baths containing a $\mathrm{Na}^{+}-\mathrm{Krebs}$ solution. The solution was continuously equilibrated with $5 \%$ carbon dioxide in oxygen, resulting in a $\mathrm{pH}$ of 7.4 [10]. The segments were mounted on two L-shaped metal prongs (50-200 $\mu \mathrm{m}$ in diameter). One prong was connected to a force-displacement transducer (FT03C; Grass Instruments, Quincy, MA, USA) attached to a computer (486 LOOP, Phoenix Technologies, San Jose, CA, USA) to record isometric tension. The other prong was connected to a displacement device, allowing fine adjustment (with an accuracy of $2.5 \mu \mathrm{m}$ ) of the distance between the two parallel prongs. The segments to be tested were given an initial passive load $(0.2-3.0 \mathrm{mN})$ through adjustment of the distance between the two metal prongs. The tension was chosen with regard to the type of segment (bronchial or arterial) investigated and adapted to variations in outer diameter and length. The specimens were subsequently allowed to stabilize at the selected tension for $90 \mathrm{~min}$. The contractile capacity of each tissue segment was examined through exposure to a potassium-rich $(60 \mathrm{mM})$ buffer. Only segments exhibiting reproducible contractions $(<$ $10 \%$ variation between the two tests) were included in the study. In order to study relaxation capacity, the segments were submaximally precontracted with histamine $\left(3 \times 10^{-6}\right.$ $\mathrm{M}$ and $10^{-5} \mathrm{M}$ in arteries and airways, respectively), which has been shown to elicit a stable contraction throughout the course of an experiment [5].

In most experiments, the concentration/response relationship for agonists was determined by the cumulative application of increasing drug concentrations. There were no differences in the response to PACAP 38 when concentration/response curves obtained by cumulative application were compared to those obtained using a single-dose procedure [11]. The integrity of the vascular endothelium was assessed by measuring the dilator response to acetylcholine [12].

In comparing the effects of PACAP and VIP, the dissected bronchial segments were divided into two matching pieces, one used to analyse the effects of PACAP and the other to analyse the effects of VIP. The tests were performed in parallel in separate tissue baths. The effects of PACAP and VIP on pulmonary arterial segments were analysed using the same procedure. Some bronchial segments did not respond to the cumulative application of VIP. To these segments one dose of PACAP $\left(10^{-7} \mathrm{M}\right)$ was applied 3 min after the highest concentration of VIP was given.

The dilatory responses were standardized using the maximal dilatory response induced by the investigated dilatory agents (PACAP, VIP) expressed as a percentage of the contraction induced by the precontracting agent (histamine) (Imax). A separate Imax was calculated for each experiment. To obtain the negative logarithm of the agonist (PACAP, VIP) concentration eliciting half the maximal response, (pEC50) the log concentration/response relationship was approximated by linear regression analysis of the data within the $5-95 \%$ confidence interval.

\section{Solutions and drugs}

Buffers. Standard buffer $\left(\mathrm{Na}^{+}-\mathrm{Krebs}\right.$ solution) contained (mM): $\mathrm{NaCl} 119, \mathrm{KCl} 4.6, \mathrm{CaCl}_{2} 1.5, \mathrm{MgCl}_{2} 1.2, \mathrm{NaHCO}_{3}$ $15, \mathrm{NaH}_{2} \mathrm{PO}_{4} 1.2$, glucose 11. The potassium-rich buffer contained the same components but with the $\mathrm{NaCl}$ replaced with $59.5 \mathrm{mM} \mathrm{NaCl}$ and with $59.5 \mathrm{mM} \mathrm{KCl}$. Analyticalgrade chemicals and double-distilled water were used for preparing all solutions.

Drugs. Acetylcholine hydrochloride and histamine dihydrochloride were obtained from Sigma (St Louis, MO, USA), PACAP 38 and VIP (Peninsula Laboratories, San Carlos, CA, USA) were dissolved in saline containing bovine serum albumin (1\%), further diluted in saline and used in the experiments within $30 \mathrm{~min}$. The use of bovine serum albumin did not affect the segments. The concentrations of the agents are expressed as the final molar concentrations in the baths.

\section{Statistics}

All results are expressed as means \pm SEM. Statistical comparisons were made using Student's t-test for unpaired data, and p-values of $<0.05$ were accepted as statistically significant. The number of donors involved is represented by $z$ and the number of experiments performed by $n$.

\section{Results}

Thin PACAP-like immunoreactive nerve fibres occurred, in moderate numbers, in the airway smooth muscle of human bronchi and pulmonary blood vessels as well as in connection with seromucous glands (fig. 1). A few PACAP-like immunoreactive fibres could also be seen beneath the epithelium. Control sections, exposed to antiserum that had been preabsorbed with an excess amount of antigen, showed no immunoreactivity. Neither did controls for nonspecific binding including normal rabbit serum without primary antibody and secondary antibody alone (not shown).

PACAP 38 induced concentration-dependent relaxation of human small bronchial segments, and dilation of corresponding pulmonary arterial segments, precontracted by histamine (fig. 2). The onset of PACAP 38-induced dilatory responses in arterial segments occurred $<30 \mathrm{~s}$ after 

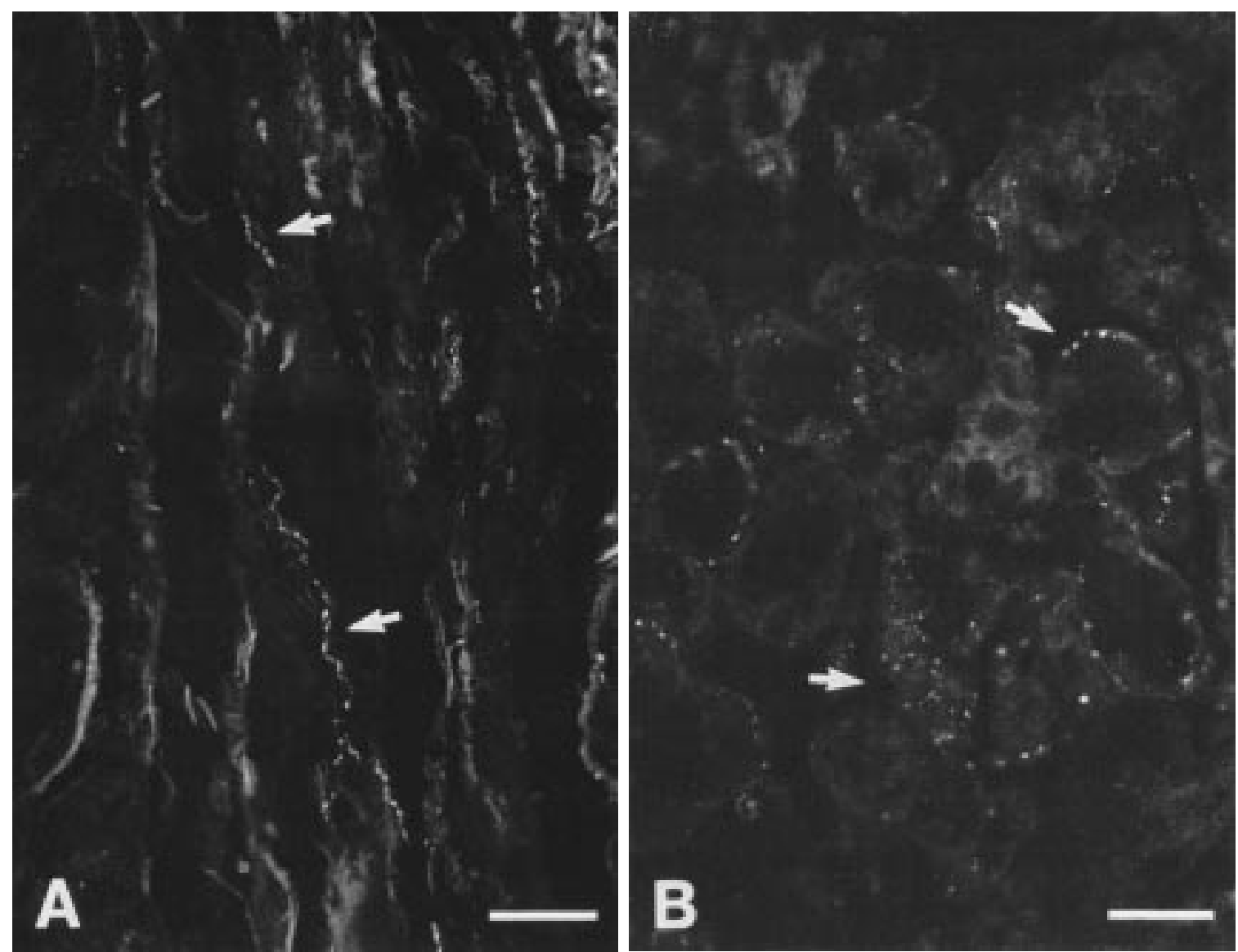

Fig. 1. - Pituitary adenylate cyclase-activating peptide (PACAP)-like immunoreactivity in human lung. A moderate number of fine varicose PACAPlike immunoreactive nerve fibres can be seen: A) in the smooth muscle layer of the bronchi; and B) in connection with seromucous glands.

addition of PACAP 38 to the bath, whereas the peak dilatory response was obtained in $2-4 \mathrm{~min}$. In the bronchial segments, the response was slower than in the arterial segments with an onset time of $1 \mathrm{~min}$ and a peak relaxant response within $10 \mathrm{~min}$.

The (Imax) induced by PACAP 38 was $50 \pm 4 \%\left(3 \times 10^{-7}\right.$ $\mathrm{M}, \mathrm{n}=20)$ in human bronchial segments and $35 \pm 5 \%\left(10^{-7}\right.$ $\mathrm{M}, \mathrm{n}=15)$ in corresponding pulmonary arterial segments. Larger doses of PACAP 38 did not elicit any further relaxation. There were no differences in PACAP 38 potency for airways and pulmonary arteries. The potency and effectiveness of PACAP 38 on precontracted human bronchial and pulmonary arterial segments are summarized in table 1 and concentration/response curves shown in figure 2 .

In a separate set of experiments, the dilatory response to PACAP 38 was compared with that to VIP. One bronchial segment and one pulmonary arterial segment was obtained from nine different donors. Each segment was subsequently divided into two identical segments, one used for PACAP and the other for VIP analyses. In the pulmonary arteries, both PACAP 38 and VIP relaxed all segments tested. There was no significant difference between the pEC50 and Imax values obtained (fig. 2a). In the bronchi, PACAP relaxed all segments tested, whereas VIP only relaxed segments from three (Imax 40 $\pm 24 \%$, pEC 50: $7.95 \pm$ $0.51, n=3$, fig. $2 b$ ) of nine patients. However, application of PACAP $\left(10^{-7} \mathrm{M}\right)$ to the six "nonresponding" segments resulted in marked dilation (fig. 2c).

\section{Discussion}

The present study demonstrates the presence of PACAPlike immunoreactive nerve fibres in association with bronchial smooth muscle, small blood vessels and seromucous glands in the human respiratory tract, as well as the potent bronchodilatory effect of PACAP 38. The presence of PACAP-like immunoreactivity in the airways of primates and rodents has previously been reported $[5,6]$ and it has been proposed that PACAP-like immunoreactive nerve fibres may be more abundant than VIP-containing nerve fibres in nonvascular smooth muscle in humans [7]. PACAP 27 and PACAP 38 have been reported to induce relaxation of precontracted guinea-pig airways in vitro $[5$, $13]$ and to inhibit histamine- and allergen-induced bronchoconstriction in vivo $[14,15]$. PACAP 27 seems to be equipotent with the clinically utilized $\beta$-adrenoreceptor agonist salbutamol in vitro [16], whereas the bronchodilatory effect of PACAP 38 is reported to be more sustained than that of PACAP 27 [15]. No differences in PACAP sensitivity between the human bronchi and pulmonary arteries could be demonstrated in the present paper, but relaxation seemed to be more pronounced in the airways. The latter is in agreement with previous data on guineapig airways, whereas the lack of difference in sensitivity stands in contrast to previous findings in guinea-pig [5].

The mechanisms of action of PACAP are not known in detail, but, in guinea-pig airways, PACAP-induced smooth 

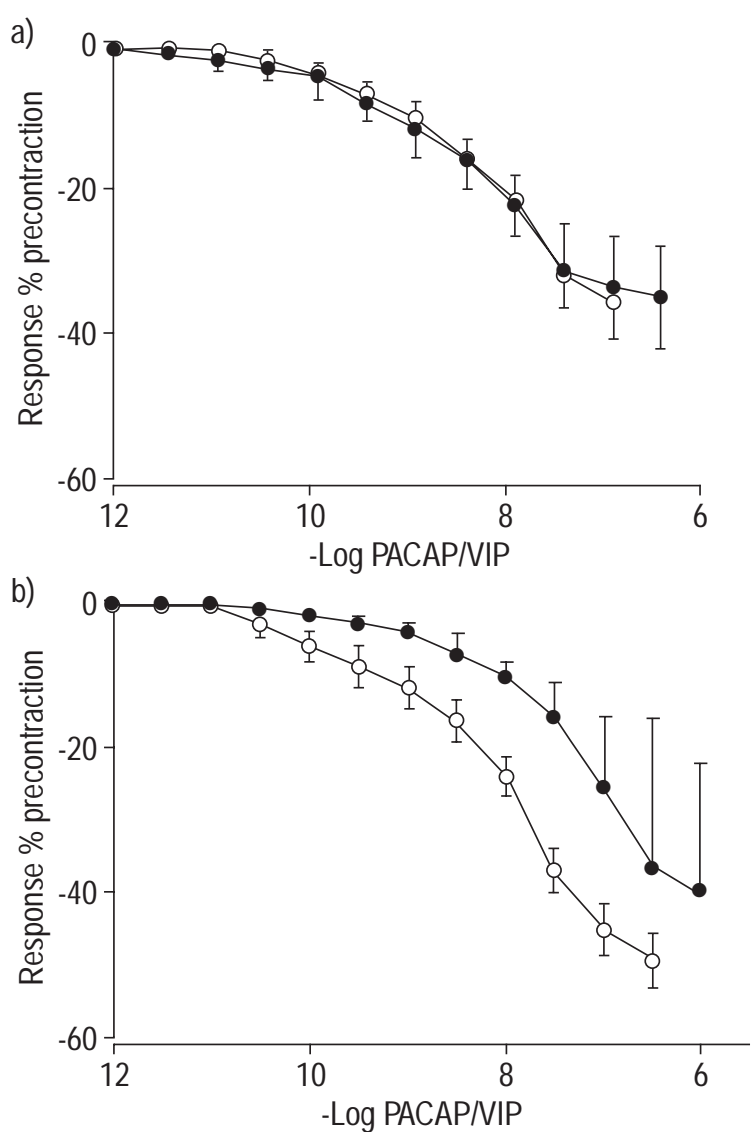

c)

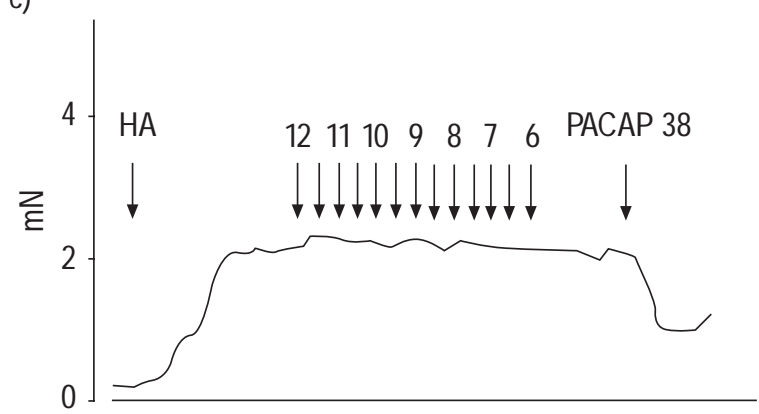

Fig. 2. - Concentration/response curves for pituitary adenylate cyclaseactivating peptide (PACAP) $38(\mathrm{O})$ and vasoactive intestinal peptide $(\mathrm{VIP})(\mathrm{O})$ in: a) histamine $\left(3 \times 10^{-6} \mathrm{M}\right)$ precontracted pulmonary arterial segment; and b) histamine $\left(10^{-5} \mathrm{M}\right)$ precontracted human bronchial segments. VIP failed to relax bronchial segments from six of nine patients; thus the presented curve (b) reflects the response of the three responding patients. Data are expressed as mean \pm SEM. c) Typical example of PACAP-induced relaxation of bronchial segments not responding to VIP. The segments were precontracted with histamine $\left(\mathrm{HA}, 10^{-5} \mathrm{M}\right)$ and challenged by the cumulative application of VIP, followed by a subsequent application of one dose of PACAP. VIP failed to induce any relaxation, whereas the application of PACAP $\left(10^{-7} \mathrm{M}\right)$ resulted in relaxation, indicating a difference between the two peptides. The VIP concentrations are -log molar. The intermediate concentrations represent $3 \times 10^{-11} \mathrm{M}$, etc.

muscle relaxation appears to be associated with cyclic adenosine monophosphate-mediated activation of calciumdependent potassium channels [16-18]. High-affinity neuromuscular binding sites for both PACAP and VIP have been localized pre- and postjunctionally in bronchial smooth muscle. At these binding sites, the affinity for both peptides is similar $[8,19]$. However, in the present
Table 1. - Pituitary adenylate cyclase-activating peptide (PACAP) 38 and vasoactive intestinal peptide (VIP)-induced relaxation of histamine precontracted human bronchial and pulmonary arterial segments

\begin{tabular}{|c|c|c|c|c|c|}
\hline Segment & $\mathrm{z}$ & $\mathrm{n}$ & $\begin{array}{l}\text { Precontraction } \\
\mathrm{mN}\end{array}$ & $\operatorname{Imax} \%$ & pEC50 \\
\hline \multicolumn{6}{|l|}{ PACAP 38} \\
\hline Bronchial & 15 & 20 & $2.5 \pm 0.6$ & $50 \pm 4$ & $8.24 \pm 0.11$ \\
\hline $\begin{array}{l}\text { Pulmonary } \\
\text { arterial }\end{array}$ & 11 & 15 & $1.7 \pm 0.7$ & $35 \pm 5^{*}$ & $8.45 \pm 0.14$ \\
\hline $\begin{array}{l}\text { VIP } \\
\text { Bronchial }\end{array}$ & 9 & $6(9)$ & $2.2 \pm 0.4$ & $0^{+}$ & - \\
\hline $\begin{array}{l}\text { Pulmonary } \\
\text { arterial }\end{array}$ & 9 & 9 & $1.1 \pm 0.2$ & $34 \pm 7$ & $8.55 \pm 0.12$ \\
\hline
\end{tabular}

Data are presented as mean \pm SEM. ${ }^{+}:$VIP failed to relax bronchial segments from six of nine donors. Imax: maximal dilatory response induced by the dilatory agent as a percentage of precontraction; pEC50: negative logarithm of the agonist concentration eliciting half the maximal response. z: number of donors. *: $\mathrm{p}<0.05$ versus bronchial segment value.

study, VIP failed to relax human bronchial segments from six of nine patients, whereas PACAP relaxed paired segments from all of these patients. The finding that VIP causes only transient and limited relaxation of isolated human bronchi has been described by other investigators and the differences between PACAP and VIP may be explained by a susceptibility of VIP to degradation by different enzymes present in the airways [20-22]. It has been reported that VIP but not PACAP 38 is cleaved by neutral endopeptidase (NEP), and a cocktail of protease inhibitors including phosphoramidon has been shown to enhance bronchial relaxation induced by VIP, but not by PACAP $[23,24]$. Furthermore, the authors have found that if PACAP 38 and VIP are preincubated with NEP, VIP loses its ability to induce plasma extravasation in guinea-pig skin, whereas the extravasation induced by PACAP is not affected (unpublished data). However, phosphoramidon has also been reported to enhance PACAP effects in other types of airway set-up [16, 25].

PACAP 38 induces secretion of saliva from all major salivary glands in the rat [26], and the presence of PACAPlike immunoreactivity in nerve fibres surrounding human seromucous glands, in the present study, might reflect a similar role for PACAP in nerve-mediated pulmonary secretion. The strong vasodilatory effect on pulmonary vessels documented in the present paper further supports a role for this peptide in the regulation of pulmonary secretion. Data derived from guinea-pig skin models suggest that PACAP 38 also has the ability to both potentiate and induce plasma extravasation [27, 28]. Taken together, these results strengthen the case for PACAP as an important endogenous mediator of bronchial smooth muscle activity but also as a regulator of pulmonary vascular smooth muscle and secretion. The question is whether the similar response induced by PACAP in bronchi and blood vessels would prevent the eventual future use of PACAP and related molecules as clinically relevant bronchodilatory agents. However, airway administration of PACAP to animals, at doses producing significant bronchodilation, seems to give rise to only 
very mild cardiovascular side effects $[14,29]$ and infusion of PACAP in the human resulted in only negligible effects on heart rate and blood pressure [30, 31].

In conclusion, the current data suggest that pituitary adenylate cyclase-activating peptide 38 is potent dilator of bronchi, present in the human lung. Pituitary adenylate cyclase-activating peptide-38 may therefore play a role in endogenous nerve-mediated airway regulation. Furthermore, pituitary adenylate cyclase-activating peptide 38 and related analogues might provide a new therapeutic angle for the treatment of asthma and related diseases. Further evaluation of potential side-effects as well as bronchodilatory experiments in humans will be needed.

\section{References}

1. Miyata A, Arimura A, Dahl RD, et al. Isolation of a novel 38 residue-hypothalamic polypeptide which stimulates adenylate cyclase in pituitary cells. Biochem Biophys Res Commun 1989; 164: 567-574.

2. Miyata A, Jiang L, Dahl RD, et al. Isolation of a neuropeptide corresponding to the $\mathrm{N}$-terminal 27 residues of the pituitary adenylate cyclase activating polypeptide with 38 residues (PACAP 38). Biochem Biophys Res Commun 1990; 170: 643-648.

3. Shigyo M, Koto H, Matsumoto K, Takata S, Aizawa H, Hara N. PACAP inhibits airway smooth muscle contraction and plasma extravasation induced by eNANC in guinea pig airways. Am J Respir Crit Care Med 1996; 153: A628.

4. Lindén A, Cardell LO, Yoshihara S, Nadel JA. Pituitary adenylate cyclase-activating peptide (PACAP) related molecules as bronchodilators. Eur Respir J 1999; 14:449-451.

5. Cardell LO, Uddman Et, Luts A, Sundler F. Pituitary adenylate cyclase activating peptide (PACAP) in guineapig lung: distribution and dilatory effects. Regul Pept 1991; 36: 379-390.

6. Uddman R, Luts A, Arimura A, Sundler F. Pituitary adenylate cyclase-activating peptide (PACAP), a new vasoactive intestinal peptide (VIP)-like peptide in the respiratory tract. Cell Tissue Res 1991; 265: 197-201.

7. Luts A, Uddman R, Alm P, Basterra J, Sundler F. Peptidecontaining nerve fibers in human airways: distribution and coexistence pattern. Int Arch Allergy Immunol 1993; 101: 52-60.

8. Lam HC, Takahashi K, Ghatei MA, Kanse SM, Polak JM, Bloom SR. Binding sites of a novel neuropeptide pituitary-adenylate-cyclase-activating polypeptide in the rat brain and lung. Eur J Biochem 1990; 193: 725-729.

9. Shivers BD, Gorcs TJ, Gottschall PE, Arimura A. Two high affinity binding sites for pituitary adenylate cyclaseactivating polypeptide have different tissue distributions. Endocrinology 1991; 128: 3055-3065.

10. Högestätt ED, Andersson KE, Edvinsson L. Mechanical properties of rat cerebral arteries as studied by a sensitive device for recording of mechanical activity in isolated small blood vessels. Acta Physiol Scand 1983; 117: 49-61.

11. Cardell LO, Uddman R, Edvinsson L. Analysis of endothelin-1-induced contractions of guinea-pig trachea, pulmonary veins and different types of pulmonary arteries. Acta Physiol Scand 1990; 139: 103-111.

12. Furchgott RF. The role of endothelium in the responses of vascular smooth muscle to drugs. Annu Rev Pharmacol Toxicol 1984; 24: 175-197.

13. Kanemura T, Tamaoki J, Chiyotani A, et al. Role of $\mathrm{Na}+-$ $\mathrm{K}+$-ATPase in airway smooth muscle relaxation by vasoactive intestinal peptide and pituitary adenylate cyclase activating peptide. Res Commun Chem Pathol Pharmacol 1993; 79: 11-22.
14. Lindén A, Yoshihara S, Chan B, Nadel JA. Inhibition of bronchoconstriction by pituitary adenylate cyclase activating polypeptide (PACAP 1-27) in guinea-pigs in vivo. Br J Pharmacol 1995; 115: 913-916.

15. Lindén A, Cardell LO, Yoshihara S, Stjärne P, Nadel JA. PACAP 1-38 as an inhaled bronchodilator in guinea pigs in vivo. Peptides 1998; 19: 93-98.

16. Yoshihara S, Lindén A, Kashimoto K, Nagano Y, Ichimura T, Nadel JA. Long lasting smooth muscle relaxation by a novel PACAP analogue in guinea-pig and primate airways in vitro. Br J Pharmacol 1997; 121: 1730-1734.

17. Araki N, Takagi K. Relaxant effect of pituitary adenylate cyclase-activating polypeptide on guinea-pig tracheal smooth muscle. Eur J Pharmacol 1992; 27: 113-117.

18. Hiramatsu T, Kume H, Yamaki K, Takagi K. Inhibition of pituitary adenylate cyclase activating polypeptide induced relaxation of guinea-pig tracheal smooth muscle by charybdotoxin. Arzneimittelforschung 1995; 45: 689-692.

19. Huang M, Shirahase H, Rorstad OP. Comparative study of vascular relaxation and receptor binding by PACAP and VIP. Peptides 1993; 14: 755-762.

20. Saga T, Said SI. Vasoactive intestinal peptide relaxes isolated strips of human bronchus, pulmonary artery, and lung parenchyma. Trans Assoc Am Physicians 1984; 97 : 304-310.

21. Tam EK, Franconi GM, Nadel JA, Caughey GH. Protease inhibitors potentiate smooth muscle relaxation induced by vasoactive intestinal peptide in isolated human bronchi. Am J Respir Cell Mol Biol 1990; 2: 449-452.

22. Foda HD, Sharaf HH, Absood A, Said SI. Pituitary adenylate cyclase-activating peptide (PACAP), a VIP-like peptide, has prolonged airway smooth muscle relaxant activity. Peptides 1995; 16: 1057-1061.

23. Gourlet P, Vandermeers A, Robberecht P, DeschodtLanckman M. Vasoactive intestinal peptide (VIP) and pituitary adenylate cyclase-activating peptide (PACAP277 but not PACAP-38) degradation by the neutral endopeptidase EC 3.4.24.11. Biochem Pharmacol 1997; 15: 509-515.

24. Bhogal R, Sheldrick RL, Coleman RA, Smith DM, Bloom SR. The effects of PACAP and VIP on guinea pig tracheal smooth muscle in vitro. Peptides 1994; 15: 1237-1241.

25. Conroy DM, St-Pierre S, Sirois P. Relaxant effects of pituitary adenylate cyclase activating polypeptide (PACAP) on epithelium-intact and -denuded guinea-pig trachea: a comparison with vasoactive intestinal peptide (VIP). Neuropeptides 1995; 29: 121-127.

26. Mirfendereski S, Tobin G, Hakanson R, Ekström J. Pituitary adenylate cyclase activating peptide (PACAP) in salivary glands of the rat: origin, and secretory and vascular effects. Acta Physiol Scand 1997; 160: 15-22.

27. Cardell LO, Stjàrne $\mathrm{P}$, Wagstaff $\mathrm{SJ}$, Agusti $\mathrm{C}$, Nadel JA. PACAP-induced plasma extravasation in rat skin. Regul Pept 1997; 15: 67-71.

28. Warren JB, Larkin SW, Coughlan M, Kajekar R, Williams TJ. Pituitary adenylate cyclase activating polypeptide is a potent vasodilator and oedema potentiator in rabbit skin in vivo. Br J Pharmacol 1992; 106: 331-334.

29. Linden A, Cardell LO, Yoshihara S, Stjàrne P, Nadel JA. PACAP 1-38 as an inhaled bronchodilator in guinea pigs in vivo. Peptides 1998; 19: 93-98.

30. Hammond PJ, Talbot K, Chapman R, Ghatei MA, Bloom SR. Vasoactive intestinal peptide, but not pituitary adenylate cyclase-activating peptide, modulates the responsiveness ofthe gonadotropin to LHRM in man. $J$ Endocrinol 1993; 137: 529-532.

31. Chiodera P, Volpi R, Capretti L, Coiro V. Effects of intravenously infused pituitary adenylate cyclase-activating polypeptide on arginine vasopressin and oxytocin secretion in man. Neuroreport 1995; 31: 1490-1492. 